\title{
Study at Two Dimensions of Thermal Transfer through a Fibers Panel Subjected to Climatic Constraints in Dynamic Frequency Regulations Established
}

\author{
Mohamed Sidya Ould Brahim1, Issa Diagne"1, Mamadou Babacar Ndiaye², Youssou Traore1, \\ Seydou Faye ${ }^{1}$, Cheikh Thiam¹, Pape Touty Traore ${ }^{1}$, Ablaye Fame ${ }^{1}$, \\ Sokhna Khadidiatou Ben Thiam1, Gregoire Sissoko' ${ }^{1}$
}

${ }^{1}$ Laboratory of Semiconductors and Solar Energy, Physics Department, Faculty of Science and Technology, University Cheikh Anta Diop, Dakar, Senegal

${ }^{2}$ University Institute of Technology, University of Thiès, Thiès, Senegal

Email: gsissoko@yahoo.com

How to cite this paper: Brahim, M.S.O., Diagne, I., Ndiaye, M.B., Traore, Y., Faye, S., Thiam, C., Traore, P.T., Fame, A., Thiam, S.K.B. and Sissoko, G. (2020) Study at Two Dimensions of Thermal Transfer through a Fibers Panel Subjected to Climatic Constraints in Dynamic Frequency Regulations Established. Energy and Power Engineering, 12, 135-142.

https://doi.org/10.4236/epe.2020.125010

Received: April 9, 2020

Accepted: May 8, 2020

Published: May 11, 2020

Copyright $\odot 2020$ by author(s) and Scientific Research Publishing Inc. This work is licensed under the Creative Commons Attribution International License (CC BY 4.0).

http://creativecommons.org/licenses/by/4.0/

\section{(c) (i) Open Access}

\begin{abstract}
From resolution of two-dimensional equation of heat in dynamic frequency regime, we have plotted evolution curves of temperature according to depth of material or in lateral direction. They will allow us to evaluate thermal behavior of towed material. Aim of study is to use fibers as a thermal insulating material by proposing a method for determining effective thermal insulation layer in dynamic frequency regime.
\end{abstract}

\section{Keywords}

Thermal Transfer, Heat Exchange Coefficient, Frequency Dynamic Regime, Fibers

\section{Introduction}

Controlling energy consumption in homes during hot weather, or in cold rooms requires, among other things, good thermal insulation. Problems of cost of synthetic materials and end-of-life management lead us to propose use of biodegradable materials. Thus study of thermal behavior of material for use in thermal insulation [1] [2] is of major interest in search for energy control.

Several methods for calculating transient or established dynamic regimes [3] [4] are developed for simulation of thermal behavior within material.

We propose in this study resolution in dynamic regime established by impos- 
ing boundary conditions particular to panel of fibers.

Temperature curves along material depth or in lateral direction will allow us to evaluate thermal behavior of fibers material. Influence of the thermal exchange coefficient on front face will be highlighted.

\section{Theory}

Equation of heat transfer through rectangular material to absence of internal source, is written in two dimensions (Figure 1):

$$
\alpha\left(\frac{\partial^{2} T}{\partial x^{2}}+\frac{\partial^{2} T}{\partial y^{2}}\right)=\frac{\partial T}{\partial t}
$$

$\alpha$ is thermal diffusivity coefficient of the material $\left(\mathrm{m}^{2} \cdot \mathrm{s}^{-1}\right)$ and is expressed as

$$
\alpha=\frac{\lambda}{\rho C}
$$

where:

- $\quad \rho\left(\mathrm{kg} \cdot \mathrm{m}^{-3}\right)$ is density of material,

- $\quad C\left(\mathrm{~J} \cdot \mathrm{kg}^{-1} \cdot \mathrm{K}^{-1}\right)$ is mass thermal capacity,

- $\lambda\left(\mathrm{W} \cdot \mathrm{m}^{-1} \cdot \mathrm{K}^{-1}\right)$ is thermal conductivity of material.

For method by separating variables, we propose:

$$
T(x, y, t)=X(x) \cdot Y(y) \cdot Z(t)
$$

(3) in (1) leads to following expressions:

$$
\begin{gathered}
\alpha\left(\frac{1}{X(x)} \cdot \frac{\partial^{2} X(x)}{\partial x^{2}}+\frac{1}{Y(y)} \cdot \frac{\partial^{2} Y(y)}{\partial y^{2}}\right)=\frac{1}{Z(t)} \cdot \frac{\partial Z(t)}{\partial t} \\
\left\{\begin{array}{l}
\frac{1}{Z(t)} \cdot \frac{\partial Z(t)}{\partial t}=i \cdot \omega \\
\frac{\partial^{2} X(x)}{\partial x^{2}}+\beta^{2} \cdot X(x)=0 \\
\frac{\partial^{2} Y(y)}{\partial y^{2}}+\mu^{2} \cdot Y(y)=0
\end{array}\right.
\end{gathered}
$$

Equations (5)-(7) are deduced from following relationships (8):

$$
\omega=i \alpha\left(\beta^{2}+\mu^{2}\right) \text { with } \mu=i \sqrt{\frac{i \cdot \omega}{\alpha}+\beta^{2}}
$$

Solutions of preceding equations give:

$$
\begin{gathered}
Z(t)=a \cdot \mathrm{e}^{i \cdot \omega \cdot t} \\
X(x)=a_{1} \cos \beta \cdot x+b_{1} \sin \beta \cdot x \\
Y(y)=a_{2} \cos \mu \cdot y+b_{2} \sin \mu \cdot y
\end{gathered}
$$

which gives general expression of temperature through material in form:

$$
T(x, y, t)=\left(a_{1} \cos \beta \cdot x+b_{1} \sin \beta \cdot x\right)\left(a_{2} \cos \mu \cdot y+b_{2} \sin \mu \cdot y\right)\left(\mathrm{e}^{i \cdot \omega \cdot t}\right)
$$

We apply to system boundary conditions, Equations (13)-(16), reflecting heat exchanges between faces of material and external environment: 


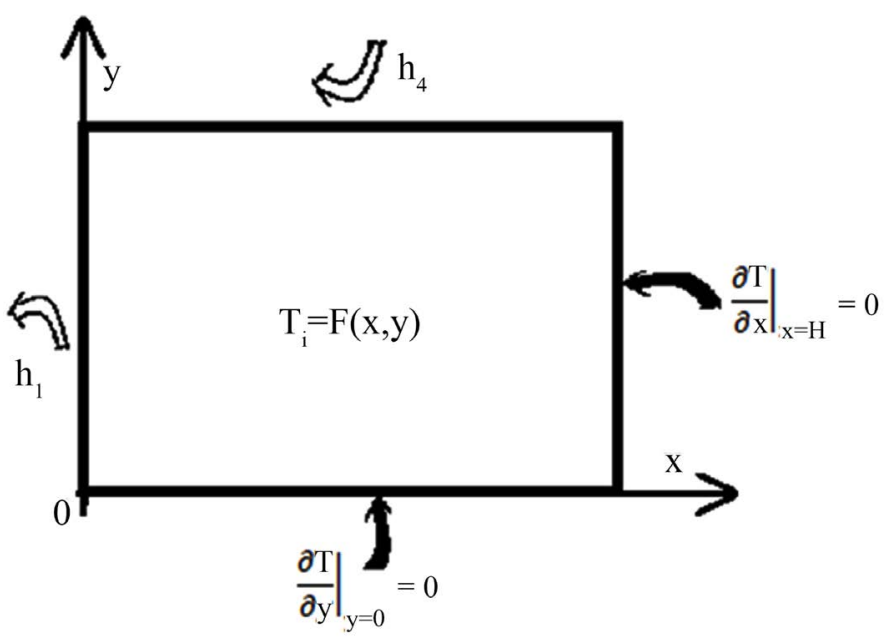

Figure 1. Study model.

$$
\left\{\begin{array}{l}
\left.\frac{\partial T}{\partial x}\right|_{x=0}=H_{1}\left(T-T_{i}\right) \\
\left.\frac{\partial T}{\partial x}\right|_{x=H}=0 \\
\left.\frac{\partial T}{\partial y}\right|_{y=0}=0 \\
\left.\frac{\partial T}{\partial y}\right|_{y=L}=-H_{4} \cdot T
\end{array}\right.
$$

with:

$$
\begin{gathered}
T_{i}=T_{0} \cdot \mathrm{e}^{i \cdot \omega \cdot t} \\
H_{1}=\frac{h_{1}}{\lambda} \text { and } H_{4}=\frac{h_{4}}{\lambda}
\end{gathered}
$$

$T_{i}$ is the temperature imposed on the front face.

We pose:

$$
\begin{gathered}
X_{0}=T_{0}=k \cdot a_{1} \\
\beta \cdot b_{1}=H_{1}\left(a_{1}-X_{0}\right)
\end{gathered}
$$

we obtain:

$$
\begin{gathered}
\frac{b_{1}}{a_{1}}=\frac{H_{1}}{\beta}(1-k) \\
\tan \beta \cdot H=\frac{H_{1}}{\beta}(1-k) \\
\tan \mu \cdot L=\frac{H_{4}}{\mu}
\end{gathered}
$$

Graphical representations of Figure 2 and Figure 3 correspond to transcendental Equation (22) and Equation (23) for obtaining eigenvalues $\beta_{m}$ and $\mu_{n}$ respectively and given in Table 1 . 


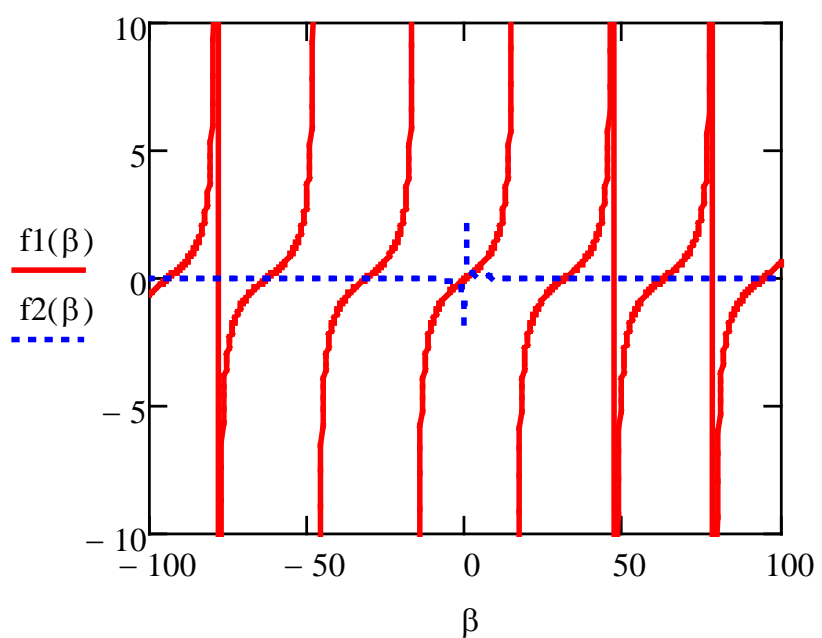

Figure 2. Eigenvalues $\beta_{m}$.

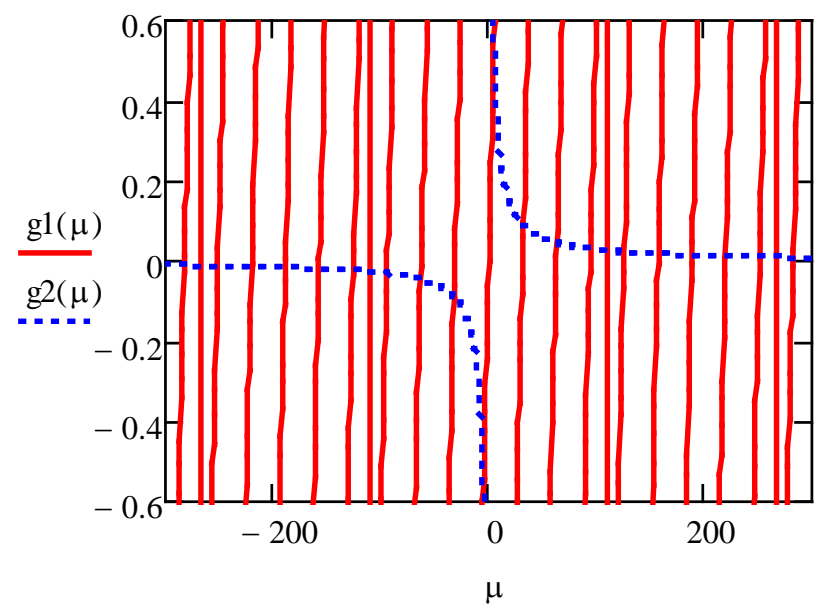

Figure 3. Eigenvalues $\mu_{n}$.

Table 1. Positives eingenvalues: $h_{1}=h_{4}=0.5 \mathrm{~W} \cdot \mathrm{m}^{-2} \cdot{ }^{\circ} \mathrm{C}^{-1}$.

\begin{tabular}{|c|c|c|c|c|c|c|c|c|c|c|c|c|}
\hline & $n$ & 1 & 2 & 3 & 4 & 5 & 6 & 7 & 8 & 9 & 0 & 11 \\
\hline$\mu_{n}, \beta_{n}$ & $\left(\mathrm{rad} \cdot \mathrm{m}^{-1}\right)$ & 5 & 32 & 65 & 65 & 96 & 127 & 158 & 192 & 219 & 250 & 284 \\
\hline
\end{tabular}

Solution of equation of heat can thus be written:

$T(x, y, t)=\sum_{m} \sum_{n} A_{m n}\left(\beta_{m} \cos \beta_{m} \cdot x+\left(H_{1}(1-k)\right) \sin \beta_{m} \cdot x\right)\left(\cos \mu_{n} \cdot y\right) \cdot \mathrm{e}^{\omega_{m n} \cdot t}$

To explain the coefficient $A_{m n}$, we pose:

$$
F(x, y)=\sum_{m} \sum_{n} A_{m n}\left(\beta_{m} \cos \beta_{m} \cdot x+\left(H_{1}(1-k)\right) \sin \beta_{m} \cdot x\right)\left(\cos \mu_{n} \cdot y\right)
$$

It can be written as:

$$
F(x, y)=\sum_{m} B_{m} \cdot\left(\beta_{m} \cos \beta_{m} \cdot x+\left(H_{1}(1-k)\right) \sin \beta_{m} \cdot x\right)
$$

with:

$$
B_{m}=\sum_{n=1}^{\infty} A_{m n}\left(\cos \mu_{n} \cdot y\right)
$$




$$
\begin{gathered}
B_{m}=\frac{1}{\int_{0}^{H}\left(\beta_{m} \cos \beta_{m} \cdot x+\left(H_{1}(1-k)\right) \sin \beta_{m} \cdot x\right)^{2} \mathrm{~d} x} \\
\cdot \int_{0}^{H} F(x, y) \cdot\left(\beta_{m} \cos \beta_{m} \cdot x+\left(H_{1}(1-k)\right) \sin \beta_{m} \cdot x\right) \mathrm{d} x \\
A_{m n}=\frac{1}{\int_{0}^{L}\left(\cos \mu_{n} \cdot y\right)^{2} \mathrm{~d} y} \int_{0}^{L} B_{m} \cdot \cos \mu_{n} \cdot y \mathrm{~d} y
\end{gathered}
$$

We replace $B_{m}$ in (38) by its expression obtained by (37), we obtain:

$$
\begin{aligned}
& A_{m n}=\frac{1}{\int_{0}^{H} \int_{0}^{L}\left(\beta_{m} \cos \beta_{m} \cdot x+\left(H_{1}(1-k)\right) \sin \beta_{m} \cdot x\right)^{2}\left(\cos \mu_{n} \cdot y\right)^{2} \mathrm{~d} x \mathrm{~d} y} \\
& \cdot \int_{0}^{H} \int_{0}^{L} F(x, y) \cdot\left(\beta_{m} \cos \beta_{m} \cdot x+\left(H_{1}(1-k)\right) \sin \beta_{m} \cdot x\right)\left(\cos \mu_{n} \cdot y\right) \mathrm{d} x \mathrm{~d} y
\end{aligned}
$$

We apply normalization condition (31):

$$
\begin{gathered}
\left\{\begin{array}{l}
N\left(\beta_{m}\right)=\int_{0}^{H}\left(\beta_{m} \cos \beta_{m} \cdot x+\left(H_{1}(1-k)\right) \sin \beta_{m} \cdot x\right)^{2} \mathrm{~d} x \\
N\left(\mu_{n}\right)=\int_{0}^{L}\left(\cos \mu_{n} \cdot y\right)^{2} \mathrm{~d} y
\end{array}\right. \\
N\left(\beta_{m}\right)=\frac{1}{2} H\left(\beta_{m}+\left(H_{1}(1-k)^{2}+H_{1}(1-k)\right)\right) \\
N\left(\mu_{n}\right)=\frac{1}{2}\left(\frac{H_{4}}{\left(\mu_{n}^{2}+H_{4}^{2}\right)}+L\right)
\end{gathered}
$$

We finally get:

$$
\begin{aligned}
& A_{m n}=\frac{4}{\left(H\left(\beta_{m}+\left(H_{1}(1-k)^{2}+H_{1}(1-k)\right)\right)\right)\left(\frac{H_{4}}{\left(\mu_{n}^{2}+H_{4}^{2}\right)}+L\right)} \\
& \cdot \int_{0}^{H} \int_{0}^{L} F(x, y) \cdot\left(\beta_{m} \cos \beta_{m} \cdot x+\left(H_{1}(1-k)\right) \sin \beta_{m} \cdot x\right)\left(\cos \mu_{n} \cdot y\right) \mathrm{d} x \mathrm{~d} y
\end{aligned}
$$

Coefficient $k$ is relative to the thermal effisitivity, it defines transmission of heat to wall of material: $0 \leq k \leq 1$.

$k=0$ : we have perfect thermal insulation behavior on surface of material;

$k=1$ : we have perfect conductor behavior on surface of material.

We worked with $k=0.85$.

Taking into account results obtained in previous studies [4] [5], we consider an average value of coefficient translating heat exchanges on surface of material: $k=0.85$.

\section{Results and Discussion}

Solution (25) of heat equation made it possible to draw simulation curves of Figures 4-7 showing evolution of temperature inside material.

Figure 4 shows evolution of temperature according depth inside material in frequency modulation. We have an accumulation of heat resulting in heating of material for $x<0.03 \mathrm{~m}$ there is no heat exchange on the lower face $y=0$. For $x>$ $0.03 \mathrm{~m}$, we have decrease in amplitude of temperature which tends at end of 


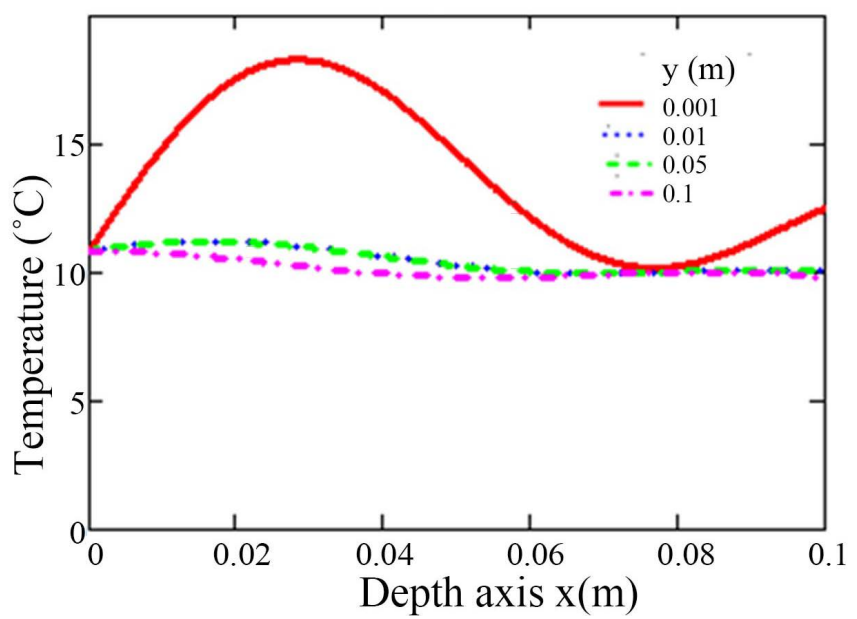

Figure 4. Evolution of temperature according to depth. $T_{i}=10^{\circ} \mathrm{C}, T_{e}=35^{\circ} \mathrm{C}, \lambda=0.174$ $\mathrm{W} \cdot \mathrm{m}^{-1} \cdot{ }^{\circ} \mathrm{C}^{-1}, h_{1}=h_{4}=0.5 \mathrm{~W} \cdot \mathrm{m}^{-2} \cdot{ }^{\circ} \mathrm{C}^{-1}$.

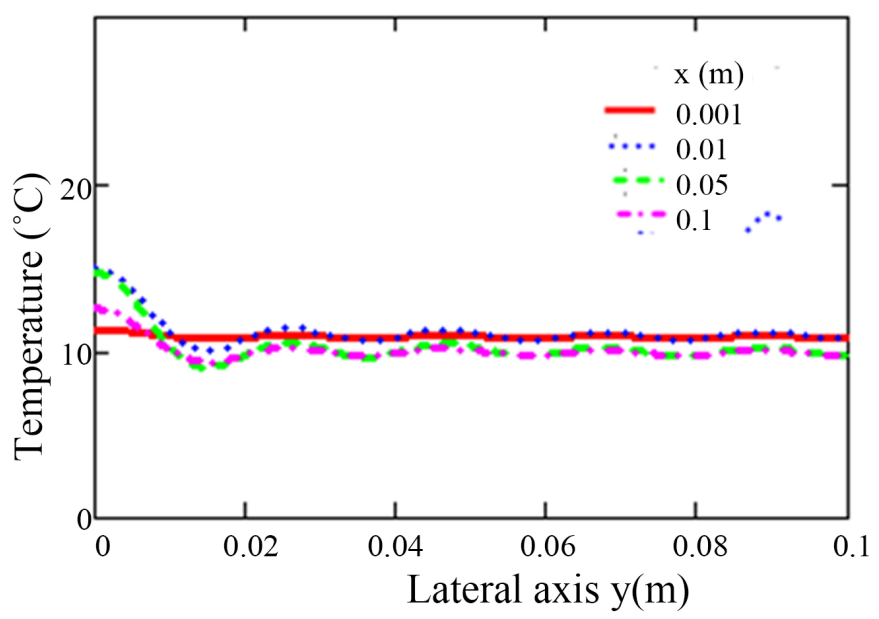

Figure 5. Evolution of temperature along lateral axis. $T_{i}=10^{\circ} \mathrm{C}, T_{e}=35^{\circ} \mathrm{C}, \lambda=0.174$ $\mathrm{W} \cdot \mathrm{m}^{-1} \cdot{ }^{\circ} \mathrm{C}^{-1}, h_{1}=h_{4}=0.5 \mathrm{~W} \cdot \mathrm{m}^{-2} \cdot{ }^{\circ} \mathrm{C}^{-1}$.

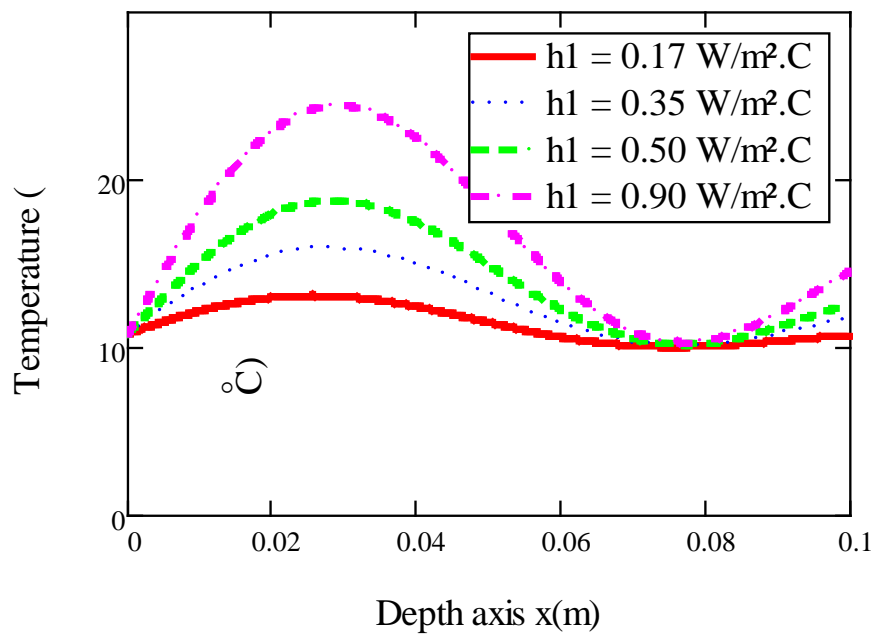

Figure 6. Evolution of temperature according to depth. Influence of heat exchange coefficient. $T_{i}=10^{\circ} \mathrm{C}, T_{e}=35^{\circ} \mathrm{C}, \lambda=0.174 \mathrm{~W} \cdot \mathrm{m}^{-1} \cdot{ }^{\circ} \mathrm{C}^{-1}, h_{4}=0.5 \mathrm{~W} \cdot \mathrm{m}^{-2} \cdot{ }^{\circ} \mathrm{C}^{-1}$. 


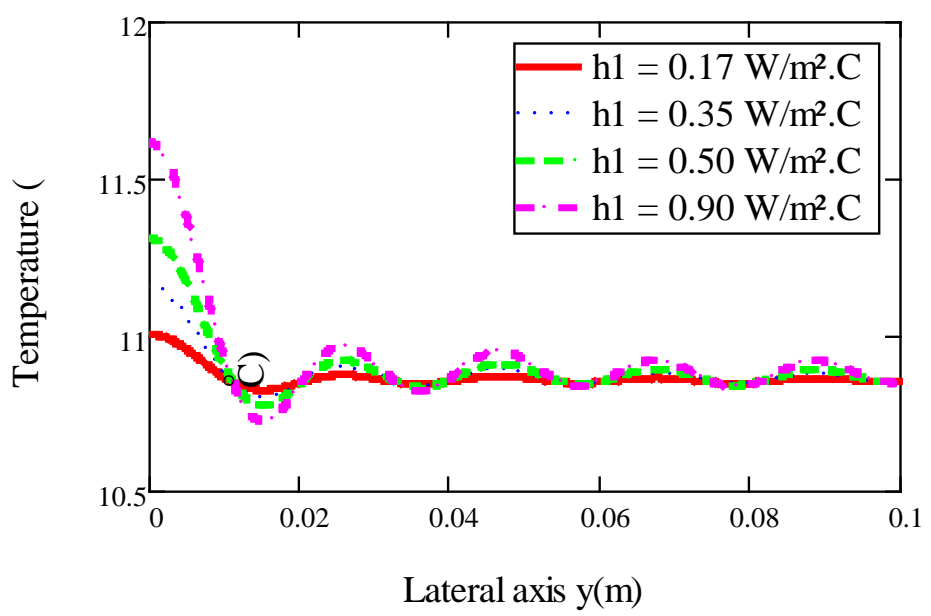

Figure 7. Evolution of temperature along lateral axis. Influence of heat exchange coefficient. $T_{i}=10^{\circ} \mathrm{C}, T_{e}=35^{\circ} \mathrm{C}, \lambda=0.174 \mathrm{~W} \cdot \mathrm{m}^{-1} \cdot{ }^{\circ} \mathrm{C}^{-1}, h_{4}=0.5 \mathrm{~W} \cdot \mathrm{m}^{-2} \cdot{ }^{\circ} \mathrm{C}^{-1}$.

excitation towards amplitude of initial temperature of material; material warms up slightly.

Figure 5 shows evolution of temperature along lateral axis. Overheating phenomenon in vicinity of $y=0$ is confirmed because there is no heat exchange with respect to outside. Beyond $y=0.02 \mathrm{~m}$, material temperature fluctuates around $10^{\circ} \mathrm{C}$, which corresponds to low overheating of material.

Figure 6 and Figure 7 show influence of heat exchange coefficient at front face on temperature. Exchange coefficient contributes significantly to heating of wall and propagation of heat along axis of depths. On other hand, along lateral axis, this influence is practically nil.

\section{Validation}

Methods of thermal characterization in numerical simulation [6] or analytical [7] [8] present results of evolutions of temperature and density of heat flux comparable through different materials.

\section{Conclusion}

Starting from resolution of equation of two-dimensional heat in frequency dynamic regime, we obtained curves which show thermal behavior of fibers material subjected to different climatic constraints. Thermal insulating nature of material is highlighted by an evanescent tendency of external excitation inside material.

\section{Conflicts of Interest}

The authors declare no conflicts of interest regarding the publication of this paper.

\section{References}

[1] Ndiaye, D., Habiboulah, L., Diagne, I., Traore, Y., Faye, S., Mbengue, B. and Sisso- 
ko, G. (2018) Study of Thermal Behavior of Wall of a Cylindrical Calorimetric Vase Covered with Flax. Journal of Scientific and Engineering Research, 5, 152-158.

[2] Bourouga, B., Goizet, V. and Bardon, J.P. (2000) The Theory Governing the Instrumentation of a thermal Sensor Parietal Low Inertia. International Journal of Thermal Sciences, 39, 96-109. https://doi.org/10.1016/S1290-0729(00)00192-6

[3] Diao, D., Ould Brahim, M.S., Diallo, H.L., Traoré, Y., Traoré, P.T., Faye, S., Diagne, I. and Sissoko, G. (2018) Evaluation of Thermal Phase Shift from the Curve of Temperature of a Kapok-Platter Material in Dynamic Frequential Regime. ARPN Journal of Engineering and Applied Sciences, 13, 9579-9583.

[4] Voumbo, M.L., Wareme, A., Gaye, S., Adji, M. and Sissoko, G. (2010) Characterization of the Thermophysical Properties of Kapok. Research Journal of Applied Sciences Engineering and Technology, 2, 143-148.

[5] Diao, D., Diene, A., Lo, M.L., Brahim, M.S.O., Traore, Y., Diallo, A.K., Diagne, I., Diallo, H.L., Boukar, M. and Sissoko, G. (2016) Study of Thermal Exchange Phenomena in Surface of Thermal Insulation Kapok-Plaster. International Journal of Pure and Applied Sciences and Technology, 33, 18-25.

[6] Traore, P.T., Ould Brahim, M.S., Traoré, Y., Ba, A., Diao, D., Faye, S., Diagne, I. and Sissoko, G. (2018) Determination of the Thermal Diffusivity to Tow Plaster by $\mathrm{Nu}$ merical Method: Influence the Biot Number and the Heat Exchange Coefficient in Transient Regime. International Journal of Innovation and Applied Studies, 22, 275-281.

[7] Bah, O.M., Ndiaye, M.B., Traore, Y., Faye, S., Diagne, I., Gomina, M. and Sissoko, G. (2018) Determination of the Study Frequency Band of a Kenaf Material from the Evolution of the Temperature and the Heat Flux Density as a Function of the Excitation Frequency. International Journal of Innovation and Applied Studies, 24, 1917-1922.

[8] Traore, Y., Diaw, E.B., Diagne, I., Ndiaye, M.B., Tamba, S., Fleur, B., Dieng, M., Diallo, A.K. and Sissoko, G. (2016) Characterization Phenomena of Thermal Transfer through an Insulating Material Kapok-Plaster Starting from Dynamic Impedance Method. Research Journal of Applied Sciences, Engineering and Technology, 12, 712-715. https://doi.org/10.19026/rjaset.12.2746 